\title{
A metabolic study of the activity of GDP-mannose dehydrogenase and concentrations of activated intermediates of alginate biosynthesis in Pseudomonas aeruginosa
}

\author{
Peter J. Tatnell, Nicholas J. Russell and Peter Gacesa* \\ Department of Biochemistry, University of Wales, Cardiff, PO Box 903, Cardiff CF1 1ST, UK
}

(Received 11 May 1992; revised 3 September 1992: accepted 17 September 1992)

\begin{abstract}
GDP-mannose dehydrogenase (GMD) is a key regulatory enzyme and the committal step in alginate biosynthesis. In this study, a metabolic approach has been used to investigate GMD activity in non-mucoid and isogenically related mucoid strains of Pseudomonas aeruginosa. Intracellular concentrations of GDP-mannose and GDPmannuronate have been quantified using HPLC separation methods, and their concentrations have been related to GMD activity and total alginate production. In all strains of $P$. aeruginos $a$ tested, GDP-mannose accumulated particularly during the exponential phase of growth in batch culture; the GDP-mannose concentrations in mucoid strains were significantly lower compared with isogenic non-mucoid strains. The product of GMD activity, GDPmannuronate, was detectable only in mucoid strains, albeit at low but relatively constant levels irrespective of growth phase. The GDP-mannose concentrations in mucoid strains were always significantly greater than those of GDP-mannuronate, indicating that GMD is a rate-limiting enzyme in the biosynthesis of alginate. Significant GMD activity and extracellular alginate production were detected only in mucoid strains. The metabolic data reported here, together with previous genetic studies, provide strong evidence that GMD is the key regulatory enzyme controlling alginate biosynthesis in mucoid strains of $\boldsymbol{P}$. aeruginosa.
\end{abstract}

\section{Introduction}

The sputum isolated from cystic fibrosis (CF) patients frequently contains mucoid strains of Pseudomonas aeruginosa. These strains secrete copious quantities of alginate (Govan \& Harris, 1986), a viscous exopolysaccharide which plays an important role in the pathogenicity of this organism (Russell \& Gacesa, 1988). During the past 20 years, $P$. aeruginosa has emerged as the major cause of morbidity and mortality amongst $\mathrm{CF}$ patients (Govan, 1988).

Bacterial alginate is a $1 \rightarrow 4$-linked linear heteropolymer consisting of $\beta$-D-mannuronate and its $\mathrm{C} 5$-epimer $\alpha$-L-guluronate (Evans \& Linker, 1973), in which the mannuronate residues can be mono- or di- $O$-acetylated (Sherbrock-Cox et al., 1984). The alginate biosynthetic pathway has been studied in Fucus gardneri (Lin \&

* Author for correspondence. Tel. 0222 874128; fax 0222 874116; email gacesa@cardiff.ac.uk.

Abbreviations: CF, cystic fibrosis; GMD, GDP-mannose dehydrogenase; PEI-cellulose; polyethyleneimine-cellulose; RP/IP, reversephase/ion-pairing; SAX, strong anion exchange.
Hassid, 1966) and Azotobacter vinelandii (Pindar \& Bucke, 1975), and a similar pathway has been proposed for P. aeruginosa (Piggott et al., 1981). The complete elucidation of the pathway in $P$. aeruginosa has proved difficult, partially due to the low enzyme activities detected in even the most overtly mucoid strains (Narbad et al., 1990). Recent molecular genetic approaches have greatly improved our understanding of both the biosynthesis of alginate and its regulation in response to environmental stimuli (see reviews by Deretic et al., 1989 , 1991; DeVault et al., 1989; Ohman et al., 1990; Russell et al., 1992; Zielinski et al., 1990).

The genes involved in alginate biosynthesis are located in three regions of the $P$. aeruginosa chromosome: the biosynthetic enzymes at 34 min (Darzins et al., 1985); a regulatory cluster at $8 \mathrm{~min}$ (Deretic et al., 1989; Deretic \& Konyecsni, 1989; Goldberg \& Ohman, 1987; Konyecsni \& Deretic, 1990 a; Mohr et al., 1991); and the muc or switching region at $68 \mathrm{~min}$ (Fyfe \& Govan, 1980; Flynn \& Ohman, 1988). The $\operatorname{alg} D$ gene is present in the biosynthetic cluster at 34 min (Darzins et al., 1985) and encodes the enzyme GDP-mannose dehydrogenase (GMD). This enzyme catalyses the essentially irreversible $\mathrm{NAD}^{+}$-dependent oxidation of GDP-mannose to GDP- 
mannuronate. Genetic studies have demonstrated that alginate production depends on transcriptional activation of the $\operatorname{alg} D$ gene in mucoid strains, which occurs in response to environmental stimuli and leads to increased amounts of the enzyme being present (Deretic et al., 1987a, b; 1990; Berry et al., 1989). Several of the regulatory gene products are involved in the control of this environmentally responsive system (Konyecsni \& Deretic, $1990 a, b$; Deretic \& Konyecsni, 1989; Wozniak \& Ohman, 1991; Kato \& Chakrabarty, 1991).

The alg $D$ gene has been sequenced (Deretic et al., $1987 a$ ) and the GMD enzyme purified and characterized. The active form exists as a hexamer with a subunit molecular mass of $48 \mathrm{kDa}$ (Roychoudhury et al., 1989), in common with a number of other four-electron transfer dehydrogenases (Feingold \& Franzen, 1981). This oligomeric nature is characteristic of allosteric enzymes which are important in regulating the flow of metabolites through particular pathways (Fersht, 1985).

On the basis of such molecular genetic studies, it has been assumed that GMD is the key regulatory enzyme of alginate biosynthesis, and is the step whereby precursors are committed to the pathway (Deretic et al., 1987b). In this paper we describe a metabolic study of the enzyme in isogenic mucoid and non-mucoid strains of $P$. aeruginosa. We demonstrate, for the first time, that the activity of GMD is regulated in a manner consistent with amounts of extracellular alginate production.

\section{Methods}

Bacterial strains. The strains of Pseudomonas aeruginosa used in this study are listed in Table 1 . The organism was grown routinely at $37^{\circ} \mathrm{C}$ on Pseudomonas Isolation Agar (PIA, Difco) or in L-broth supplemented with $0.25 \%$ glucose. Medium (1 litre) was inoculated with $5 \mathrm{ml}$ of overnight culture. The conditions for growth of Arthrobacter viscosus were as described by Preiss \& Wood (1964). The growth of cultures was monitored by turbidity measurements at $650 \mathrm{~nm}$, and total bacterial numbers were estimated by epifluorescence microscopy using acridine orange (Hobbie et al., 1977).

Preparation of nucleotide extracts. Cultures were harvested by centrifugation at $9600 \mathrm{~g}_{\mathrm{av}}$ for $10 \mathrm{~min}$ at room temperature, washed with

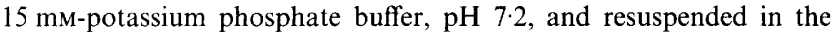
same buffer. The nucleotide extract was prepared by utilizing a protein precipitation procedure in which the bacteria were homogenized in ice-cold $0.5 \mathrm{M}$-trifluoroacetic acid; the cell debris was removed by sedimentation in a microfuge at 12000 r.p.m. for $5 \mathrm{~min}$ at $4{ }^{\circ} \mathrm{C}$. The supernatant was neutralized with freshly made, ice-cold $0.5 \mathrm{M}$-tri- $n$ octylamine in 1,1,2-trichloro-1,2,2,-trifluoroethane. The upper nucleotide-containing aqueous layer was removed and stored at $-20^{\circ} \mathrm{C}$ (Dutta \& O'Donovan, 1987). The extraction, which is optimized for the extraction of guanine-containing compounds (Dutta \& O'Donovan, 1987), is quantitative (Woodland \& Pestell, 1972) and the extracts may be stored for up to one month at $-20^{\circ} \mathrm{C}$ without measurable degradation of the GDP sugars.

Fractionation of nucleotide extract by HPLC. GDP-mannose was separated from other components by ion-pair HPLC fractionation on a C18 Apex II ODS column (Jones Chromatography Ltd, Hengoed. Wales) having a particle-size of $5 \mu \mathrm{m}$ and column dimensions of $250 \mathrm{~mm} \times 4.6 \mathrm{~mm}$ (i.d.) using $100 \mathrm{~mm}-\mathrm{KH}_{2} \mathrm{PO}_{4}$ buffer, $\mathrm{pH} 5.7$, supplemented with $5 \mathrm{~mm}$-tetrabutylammonium phosphate as the eluant at a flow rate of $1.5 \mathrm{ml} \mathrm{min}{ }^{-1}$.

GDP-mannuronate was separated from other components by anionexchange HPLC fractionation on a Zorbax SAX column (Jones Chromatography) having a particle size of $5 \mu \mathrm{m}$ and column dimension of $250 \mathrm{~mm} \times 4.6 \mathrm{~mm}$ (i.d.). The column was eluted at a flow rate of $1 \mathrm{ml}$ $\min ^{-1}$ with a buffer gradient system consisting of eluant A [15 mM$\mathrm{KH}_{2} \mathrm{PO}_{4}, \mathrm{pH} 4.5,10 \%(\mathrm{v} / \mathrm{v})$ methanol] and eluant $\mathrm{B}$ [400 mm$\mathrm{KH}_{2} \mathrm{PO}_{4}, \mathrm{pH} 4 \cdot 1,650 \mathrm{~mm}-\mathrm{KCl}, 10 \%(\mathrm{v} / \mathrm{v})$ methanol]; the percentage of eluant $\mathrm{B}$ in the buffer system was increased linearly from $0 \%$ to $25 \%$ during the initial $5 \mathrm{~min}$, to $28 \%$ at $35 \mathrm{~min}, 100 \%$ at $40 \mathrm{~min}$ and this final percentage of eluant $\mathbf{B}$ maintained for $5 \mathrm{~min}$. The column was reequilibated with $100 \%$ eluant $\mathrm{A}$ before application of the next sample.

For each type of HPLC separation, the nucleotide extracts $(100 \mu 1)$ were filtered through a $0.45 \mu \mathrm{m}$ ACRO LC13 filter (Gelman Sciences) just prior to injection. The nucleotides were detected by monitoring the absorbance of the column effluent at $254 \mathrm{~nm}$ using a Cecil CE212 spectrophotometer equipped with a $1 \mathrm{~cm}$ pathlength flow-through cell. The nucleotide-sugars were quantified by comparing their peak areas to those of known standards.

Acid phosphatase treatment of nucleotide extracts. Acid phosphatase $(5 \mathrm{mg}$, Sigma) was added to each nucleotide extract $(1 \mathrm{ml})$ and incubated for $5 \mathrm{~h}$ at $25^{\circ} \mathrm{C}$ to remove terminal phosphate groups (phosphodiester linkages are unaffected by this treatment). The enzyme was removed by precipitation with trifluoroacetic acid (see above), and the extract re-analysed by HPLC using the same conditions as described above.

Enzyme assays. Cell-free extracts were prepared according to the procedure of Pugashetti et al. (1983) and GMD activity assayed according to the method of Preiss (1964). Specific enzyme activities were corrected for endogenous dehydrogenase activity $(<80 \mathrm{pmol}$ $\left.\mathrm{min}^{-1} \mathrm{mg}^{-1}\right)$. Protein concentration was determined using the procedure of Bradford (1976).

Isolation of alginate. Alginate was isolated from liquid cultures and purified using the method of Narbad et al. (1988).

Thin-layer chromatography. A modification of the TLC system of Randerath \& Randerath (1964), with PEI-cellulose containing fluorescent indicator as the adsorbent, was used to identify GDP-mannose and GDP-mannuronate. The nucleotide sugars were analysed directly, or in some instances, after acid hydrolysis $(0.01 \mathrm{M}-\mathrm{HCl}$ for $15 \mathrm{~min}$ at $100^{\circ} \mathrm{C}$ ). Chromatograms were developed using the following procedure. Plates were placed in $0.2 \mathrm{M}-\mathrm{LiCl}$ for $1 \mathrm{~min}$, transferred without drying to $1.0 \mathrm{M}-\mathrm{LiCl}$ and after $3.5 \mathrm{~min}$ transferred to $1.6 \mathrm{M}-\mathrm{LiCl}$. The nucleotides and nucleotide sugars were visualized using UV light $(254 \mathrm{~nm})$. The sugar components derived from the acid-hydrolysed samples were visualized after spraying the chromatograms with alkaline silver nitrate reagent (Trevelyan et al., 1950). The relative mobilities of samples were compared to those of appropriate standards. The mannuronate standard was prepared by treating commercially available mannurono-6,3-lactone with $1 \%(\mathrm{v} / \mathrm{v})$ triethlyamine (Miyamoto \& Nagase, 1981).

Isolation of GDP-mannuronate from Arthrobacter viscosus. The nucleotide sugar GDP-mannuronate is not commercially available and therefore it was prepared by oxidation of GDP-mannose using GMD isolated from Arthrobacter viscosus according to the procedure of Preiss (1966). Separation of authentic GDP-mannuronate from assay components such as NAD ${ }^{+}$and GDP-mannose was achieved using the Zorbax SAX HPLC system described above. The GDP-mannuronate peak fractions were collected and pooled; the solution was desalted by 
Table 1. Bacterial strains

\begin{tabular}{lll}
\hline \hline Strain & \multicolumn{1}{c}{ Genotype/phenotype } & Reference \\
\hline P. aeruginosa & Prototrophic, Alg $^{-}$(non-mucoid) & Holloway et al. (1979) \\
PAO 1 & ${\text {FP2 } \text { Alg }^{+} \text {muc-2 leu-38 (mucoid) }}^{+}$Fyfe \& Govan (1980) \\
PAO 568 & Prototrophic, Alg CF isolate (mucoid) & Ohman \& Chakrabarty (1981) \\
FRD 1 & Spontaneous revertant of FRD 1, Alg algS(off) (non-mucoid) & Ohman \& Chakrabarty (1982) \\
FRD 2 & Wild-type strain equivalent to NRRL B1973 (ATCC 19584) & Preiss (1964) \\
A. viscosus & NCIMB 9729 &
\end{tabular}

adsorption on activated charcoal (NoritA) and eluted with $50 \%(\mathrm{v} / \mathrm{v})$ aqueous ethanol containing $1 \%(\mathrm{v} / \mathrm{v}) \mathrm{NH}_{3}$. The GDP-mannuronate solution was lyophilized and re-dissolved in a minimum volume of distilled $\mathrm{H}_{2} \mathrm{O}$.

The chemical identity of the prepared standard of GDP-mannuronate was confirmed using several independent techniques. First, the concentrations of substrates and products of the enzymic reaction were estimated at various time intervals to ascertain the stoichiometry of the reaction. This involved anion-exchange HPLC fractionation of the intermediates, as described above. From a quantification of the time-dependent change in concentrations of the reactants it was determined that 2 moles of $\mathrm{NAD}^{+}$were reduced stoichiometrically to 2 moles of $\mathrm{NADH}+\mathrm{H}^{+}$while 1 mole of GDP-mannose was converted to 1 mole of a more negatively-charged compound which was presumed to be GDP-mannuronate. Second, the presence of uronic acid in the putative GDP-mannuronate was confirmed using the assay of Blumenkrantz \& Asboe-Hansen (1973). The nucleotide component was also confirmed as GDP by its characteristic UV absorption spectra at $\mathrm{pH}$ values of 1,7 and 12 , which were compared with those of the GDP in authentic GDP-mannose. Third, the component parts of the nucleotide sugar, i.e. GDP and mannuronate, were identified by thinlayer chromatography of the sample following acid hydrolysis (see above) in which they co-migrated with authentic GDP and mannuronate standards.

Statistical analysis of data. Results are presented as means \pm standard deviations where $n$ equals the number of experimental determinations. When appropriate, probability values have been calculated using Student's paired $t$-test with statistical significance set at the $90 \%$ confidence limit.

\section{Results}

Detection of GDP-mannose and GDP-mannuronate in nucleotide extracts of $P$. aeruginosa

A variety of HPLC separation systems utilizing a wide range of buffer concentrations and $\mathrm{pH}$ gradients were tested for their ability to separate the components of nucleotide extracts from $P$. aeruginosa, in particular to facilitate the quantification of GDP-mannose and GDPmannuronate. No one system proved capable of giving good enough separations to quantify both components on a single chromatogram. Instead, two chromatographic systems having different bases for the separation were used, namely a reverse-phase (RP) column in conjunction with the ion-pairing (IP) agent tetrabutylammonium phosphate for separation and quantification of GDP-mannose and a strong-anion-exchange (SAX) system for GDP-mannuronate. These gave good baseline separations of the key nucleotide sugars (Figs 1 and 2), although there was some peak broadening of GDPmannuronate. A comparison of $P$. aeruginosa strains showed that GDP-mannuronate could be detected only in mucoid strains.

The retention times of GDP-mannose and GDPmannuronate corresponded with those of authentic standards and were confirmed by co-chromatography. In the RP/IP system GDP-mannose eluted from the column at approximately $20 \mathrm{~min}$, while in the SAX system GDP-mannuronate eluted at approximately 36 min. These times varied marginally depending on the overall nucleotide composition of the extract, which changed with the growth phase at which cultures were harvested. However, the addition of small quantities of standards to the extracts confirmed the identity of the peaks. Pre-treatment of nucleotide extracts with acid phosphatase also altered their overall composition, which in turn changed marginally the retention times of GDP-mannose and GDP-mannuronate in the extracts and of exogenously added authentic standards.

\section{Identification of GDP-mannose and GDP-mannuronate in nucleotide extracts of $P$. aeruginosa}

Once the retention times for each nucleotide-sugar had been determined, peaks were collected and pooled for further structural identification. The identity of GDPmannose was confirmed firstly by its UV absorption spectrum, which was identical to that of a standard solution of GDP-mannose in the same RP/IP buffer system as used for the HPLC separation, and secondly by the fact that it co-migrated with an authentic GDPmannose standard (dissolved in either water or the RP/IP buffer system) after thin-layer chromatography on PEI-cellulose. The presence of the hexose moiety, i.e. mannose, was confirmed by a positive colour reaction in the phenol/ $\mathrm{H}_{2} \mathrm{SO}_{4}$ test (Dubois et al., 1956).

GDP-mannuronate was identified on the basis of the presence of a uronic acid moiety as determined by the 


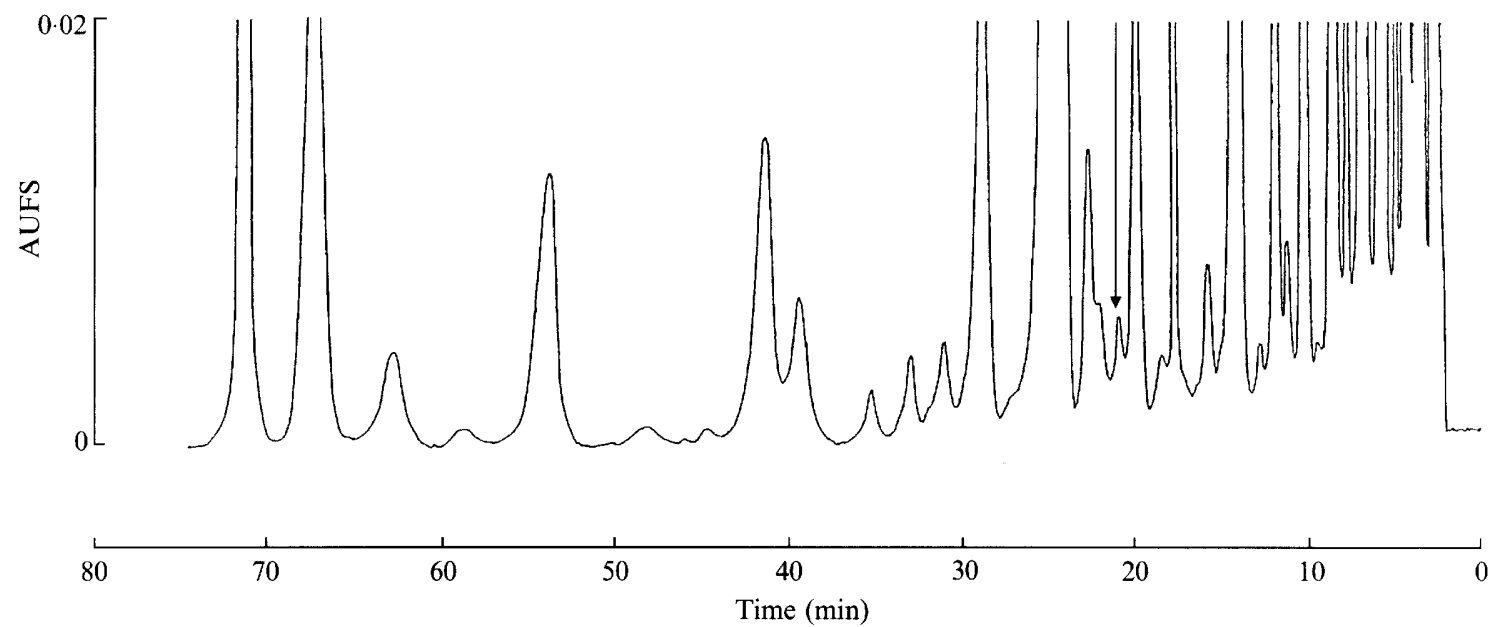

Fig. 1. Fractionation of a $P$. aeruginosa FRD1 nucleotide extract using reverse-phase ion-pair HPLC. The nucleotide extract was obtained from cultures harvested at the late exponential phase of growth and analysed directly without prior alkaline phosphatase treatment. The peak corresponding to GDP-mannose is indicated by an arrow.

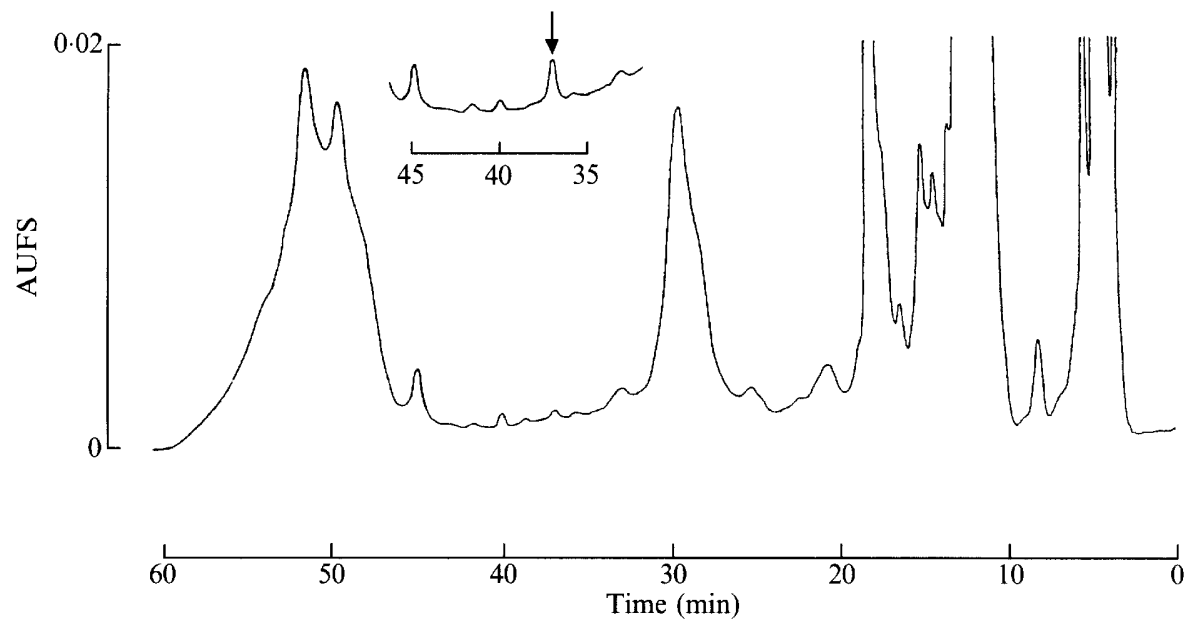

Fig. 2. Fractionation of a $P$. aeruginosa FRD1 nucleotide extract using anion-exchange HPLC. The lower trace represents nucleotide extract obtained from cultures harvested at the late exponential phase of growth and analysed directly without prior alkaline phosphatase treatment. The upper trace represents the same sample containing added GDP-mannuronate $(0 \cdot 2 \mu \mathrm{g})$. For the sake of clarity, only the region of the trace around the GDP-mannuronate peak is shown. The peak corresponding to GDP-mannuronate is indicated by an arrow.

Blumenkrantz and Asboe-Hansen assay (see Methods) and its UV absorption spectrum compared with other guanosine-containing compounds, including authentic GDP-mannuronate prepared from GDP-mannose using the isolated GMD from $A$. viscosus. The standards were dissolved in the effluent collected from the HPLC column at a retention time corresponding to that of GDPmannuronate; this column effluent was used as the blank. Further confirmation of identity was provided by thin-layer chromatography on PEI-cellulose, when the
GDP-mannuronate from $P$. aeruginosa co-migrated with the prepared standard sample of GDP-mannuronate.

Quantification of GDP-mannose and GDP-mannuronate in nucleotide extracts of $P$. aeruginosa

Quantification of both nucleotide sugars was achieved by comparison of peak areas with standards of known concentrations (see Tables 2 and 3). Treatment of the nucleotide extracts with acid phosphatase reduced the 

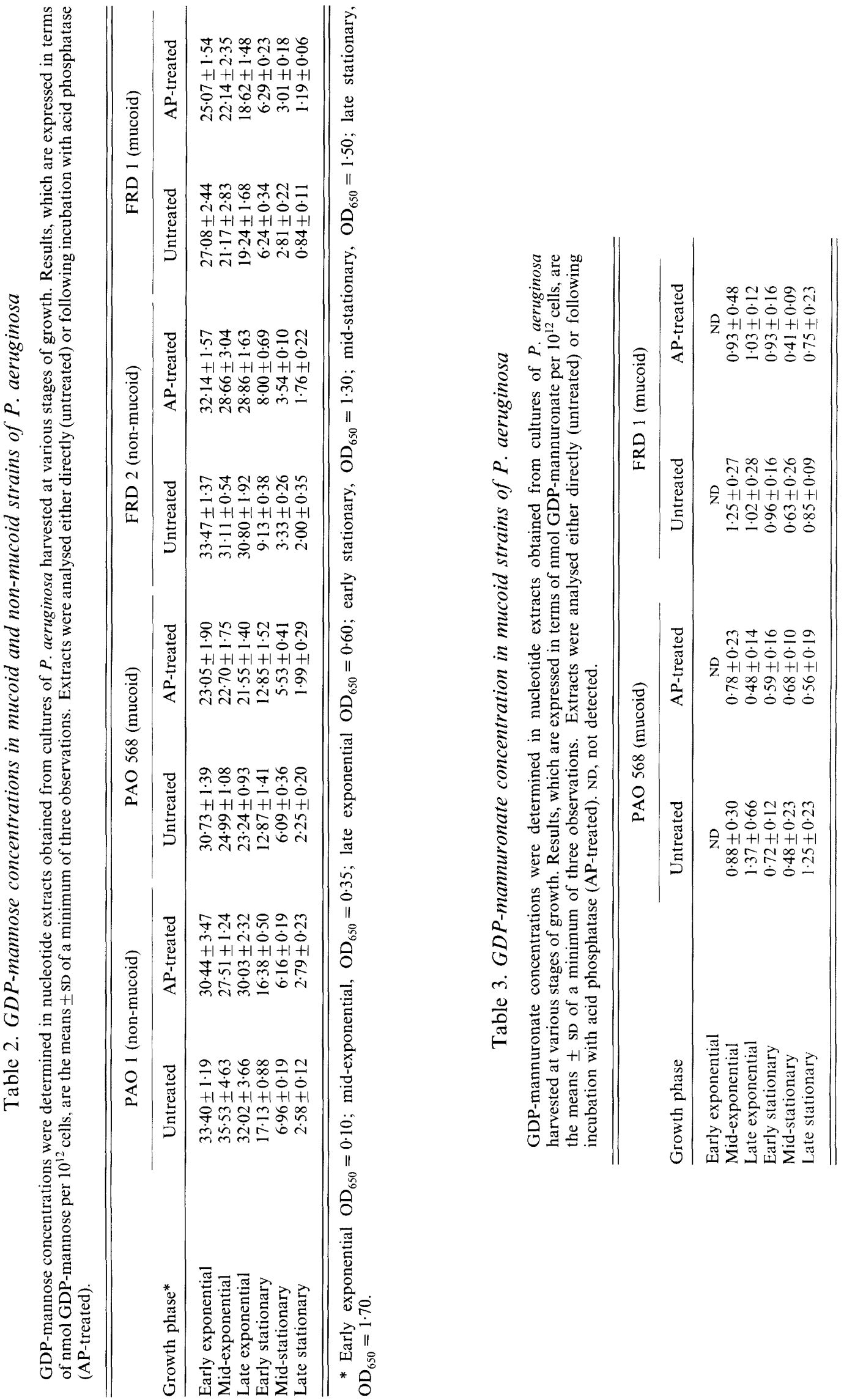
Table 4. GMD activity in mucoid strains of

$$
P \text {. aeruginosa }
$$

The specific activity of GMD was assayed in cell-free extracts of $P$. aeruginosa harvested at various stages of growth. Results, which have been corrected for endogenous activity, are expressed as means $\pm S D$ (number of estimates $=6$ ). The specific activity of non-

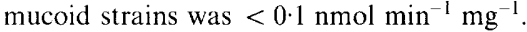

\begin{tabular}{lrr}
\hline \hline & \multicolumn{2}{c}{$\begin{array}{c}\text { Specific activity } \\
\left.\text { (nmol } \mathrm{min}^{-1} \mathrm{mg}^{-1}\right)\end{array}$} \\
\cline { 2 - 3 } Growth phase & \multicolumn{1}{c}{ PAO 568} & \multicolumn{1}{c}{ FRD 1 } \\
\hline Early exponential & $7 \cdot 0 \pm 1 \cdot 9$ & $4 \cdot 3 \pm 0 \cdot 3$ \\
Mid-exponential & $7 \cdot 0 \pm 2 \cdot 9$ & $6 \cdot 8 \pm 1 \cdot 4$ \\
Late exponential & $11 \cdot 5 \pm 1 \cdot 3$ & $8 \cdot 6 \pm 1 \cdot 4$ \\
Early stationary & $15 \cdot 2 \pm 0 \cdot 3$ & $21 \cdot 3 \pm 2 \cdot 6$ \\
Mid-stationary & $16 \cdot 1 \pm 1 \cdot 3$ & $28 \cdot 9 \pm 0 \cdot 9$ \\
Late stationary & $15 \cdot 1 \pm 0 \cdot 6$ & $22 \cdot 7 \pm 4 \cdot 8$ \\
\hline \hline
\end{tabular}

total number of peaks in the chromatogram but did not alter significantly the quantitative estimation of GDPmannose. The lower limit of detection of GDP-mannose using the RP/IP HPLC system was $50 \mathrm{pmol}$ per $\mathrm{ml}$ of extract chromatographed. This limiting value is 20 -fold less than the lowest amount of GDP-mannose detected in any of the samples from mucoid or non-mucoid strains.

The concentrations of GDP-mannose in nucleotide extracts of PAO and FRD strains of $P$. aeruginosa depended on the time of harvesting during batch culture: the amounts did not alter during the exponential phase of growth but decreased 10-20-fold during the stationary phase (Table 2). There was a small, but statistically significant $(P<0 \cdot 12)$, difference between the amounts of GDP-mannose in pairs of mucoid/non-mucoid isogenic strains except at late stationary phase.

GDP-mannuronate could be detected only in the mucoid strains PAO 568 and FRD 1 and there was no statistically significant variation $(P>0.20)$ in the concentration of this metabolite during growth in batch culture (Table 3). The lower limit of detection of GDP- mannuronate using the Zorbax SAX HPLC system (see Methods) was $0.1 \mathrm{nmol}$ per $\mathrm{ml}$ of extract chromatographed. This limiting value is threefold less than the lowest amount of GDP-mannuronate detected in mucoid strains.

\section{GMD activity in P. aeruginosa}

The activities of GMD in the mucoid strains PAO 568 and FRD 1 are given in Table 4 . The enzyme activity in corresponding isogenic non-mucoid strains was barely

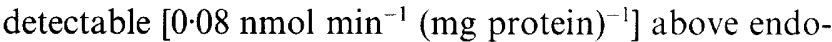
genous dehydrogenase activity. As batch cultures progressed from exponential into stationary phase, the enzyme activity increased approximately twofold in $P$. aeruginosa PAO 568 and fivefold in strain FRD 1 (Table 4). The specific activity of GMD in the clinical strain FRD 1 was similar to that in the laboratory strain PAO 568 during exponential phase, but significantly more $(P<0 \cdot 1)$ during stationary phase.

\section{Production of extracellular alginate}

The production of extracellular alginate was measured by quantification of the uronic acid content in extracellular material secreted into the culture medium by mucoid and non-mucoid strains (Table 5). The amounts produced by the non-mucoid strains PAO 1 and FRD 2 were very small compared with the mucoid strains. The quantity of alginate produced by the mucoid strains increased by $9-10$-fold as cultures progressed from lateexponential to early-stationary phase, after which there was no further increase.

\section{Discussion}

Mucoid and non-mucoid strains of $P$. aeruginosa are genetically competent to synthesize alginate as they all possess the alginate biosynthetic and regulatory genes (Fialho et al., 1990). The term 'mucoid' is used to

Table 5. Quantification of extracellular alginate

The alginate concentration in the extracellular material was determined as described in Methods. Results are expressed as means \pm SD of a minimum of three experiments.

\begin{tabular}{lcccc}
\hline \hline & \multicolumn{4}{c}{ Alginate produced (mg per 10 ${ }^{12}$ cells) } \\
\cline { 2 - 5 } Growth phase & PAO 1 & PAO 568 & FRD 2 & FRD 1 \\
\hline Early exponential & $0 \cdot 85 \pm 0 \cdot 05$ & $2 \cdot 75 \pm 0 \cdot 69$ & $0 \cdot 14 \pm 0 \cdot 01$ & $2 \cdot 95 \pm 0 \cdot 02$ \\
Mid-exponential & $0 \cdot 52 \pm 0 \cdot 05$ & $2 \cdot 96 \pm 0 \cdot 44$ & $0 \cdot 72 \pm 0 \cdot 01$ & $4 \cdot 15 \pm 0 \cdot 27$ \\
Late exponential & $0 \cdot 14 \pm 0 \cdot 03$ & $8 \cdot 31 \pm 0 \cdot 52$ & $0 \cdot 37 \pm 0 \cdot 02$ & $11 \cdot 64 \pm 0.95$ \\
Early stationary & $0 \cdot 23 \pm 0 \cdot 04$ & $28 \cdot 95 \pm 4 \cdot 00$ & $0 \cdot 28 \pm 0 \cdot 03$ & $38 \cdot 43 \pm 3 \cdot 63$ \\
Mid-stationary & $0 \cdot 16 \pm 0 \cdot 04$ & $30 \cdot 70 \pm 5 \cdot 19$ & $0 \cdot 27 \pm 0 \cdot 09$ & $38 \cdot 89 \pm 3 \cdot 54$ \\
Late stationary & $0 \cdot 23 \pm 0 \cdot 11$ & $25 \cdot 45 \pm 4 \cdot 10$ & $0 \cdot 47 \pm 0 \cdot 08$ & $30 \cdot 25 \pm 3 \cdot 12$ \\
\hline \hline
\end{tabular}


describe those strains which produce copious amounts of alginate and, according to the classification scheme of Phillips (1969), give the type 5 watery colonial morphology within $24 \mathrm{~h}$ on agar-based media (Govan, 1990). There has been one report (Anastassiou et al., 1987) that non-mucoid strains also produce alginate, albeit in very small quantities. In the present study, the isogenic nonmucoid strains were found to produce from 3- to 180 fold less alginate than the isogenic mucoid strain, depending on the stage of growth in batch liquid culture (Table 5). Indeed, it is possible that the small amount of uronic-acid-positive extracellular material made by nonmucoid strains was derived from a polymer other than alginate, particularly since the amount did not alter during the growth cycle. The lipopolysaccharide of some strains of $P$. aeruginosa contains small quantities of L-guluronate and D-mannuronate (Kelly et al., 1990), which could be the source of this uronic-acid-positive material.

On the basis of genetic evidence, GMD appears to be the key regulatory enzyme and the committal step for alginate biosynthesis in mucoid $P$. aeruginosa. Genetic experiments have demonstrated that the $\operatorname{alg} D$ gene, which encodes GMD, is transcriptionally activated in mucoid but not non-mucoid strains (Deretic et al., $1987 a$ ). The postulated stringent control over the $\operatorname{alg} D$ promoter leads to tight regulation of alginate biosynthesis, which is believed to be necessary as so much of the carbon and energy sources available to mucoid strains is committed to extracellular polysaccharide production (Ohman et al., 1990). Transcriptional regulation of GMD, however stringently controlled, can only influence the total quantity of enzyme which is synthesized and thereby the capacity to consume substrate. However, this type of control may not be sufficiently precise to regulate the flux through the alginate pathway in response to more immediate changes in such metabolic conditions as adenylate charge. The multi-subunit structure of the enzyme and its inhibition by various guanosine derivatives (Roychoudhury et al., 1989) support the concept that GMD could be a metabolically regulated enzyme.

Our data, based on the quantification of key metabolites, show that GMD is indeed the controlling step of the alginate biosynthetic pathway. In mucoid strains, the specific activity of GMD increases progressively with growth of the culture and alginate production. This is paralleled by a decrease in the steady-state quantity of the substrate GDP-mannose. However, the immediate product of the GMD reaction, i.e. GDP-mannuronate, remains at a low and fairly constant level regardless of the specific activity of GMD or the rate of alginate production. These observations are in accord with the concept that the rate of alginate biosynthesis is governed by the activity of GMD.
Calculations based on our data provide estimates for the GDP-mannose concentration within $P$. aeruginosa in batch culture of between $60 \mu \mathrm{M}$ in early exponential phase to $6 \mu \mathrm{M}$ in late stationary phase. Reported kinetic data for GMD provide an estimate of $15 \mu \mathrm{M}$ for the $K_{\mathrm{m}}$ for GDP-mannose (Roychoudhury et al., 1989). Therefore, the calculated concentrations of GDP-mannose in $P$. aeruginosa lie within the range of 0.4 to 4 times the $K_{\mathrm{m}}$ value for GMD. In effect, this means that the rate of flux through this step of the pathway is dependent on available GMD activity.

Using HPLC we have determined the free intracellular concentrations of GDP-mannose and GDP-mannuronate in isogenic pairs of mucoid and non-mucoid strains of $P$. aeruginosa, and have related these substrate/ product levels both to the GMD activity in cell-free extracts and to the quantity of extracellular alginate produced. The fact that we could detect GMD activity in mucoid strains is in accord with the genetic observations of others that $\operatorname{alg} D$ transcription is switched on in such strains. Moreover, the specific activity of the enzyme increased as cultures entered stationary phase in concert with an increase in the amount of alginate produced (compare Tables 4 and 5). The higher GMD activity in FRD 1 compared with PAO 568 also correlates with the greater production of alginate by the mucoid FRD strain. These metabolic data support the genetic evidence that the amount of alginate produced is governed by the activity of GMD. The rate of chemical flux through a metabolic pathway is often regulated by controlling not only the expression but also the activity of a key, ratelimiting enzyme in the pathway (Fersht, 1985). Our metabolic data on GMD activity and substrate and product levels are consistent with metabolic regulation of enzyme activity being a possibility.

The substrate of the GMD reaction, GDP-mannose, was found in comparable amounts in mucoid and nonmucoid isogenic pairs of strains, despite the large extra demand for GDP-mannose in mucoid strains making great quantities of extracellular alginate. Although the mucoid strains contained statistically significantly lower levels of GDP-mannose compared with the respective isogenic non-mucoid strains, the actual differences were small. This indicates that the flux of GDP-mannose through the enzyme is tightly regulated, even in nonmucoid strains, which probably reflects the relatively constant demand for GDP-mannose in Gram-negative bacteria for lipopolysaccharide biosynthesis (Sutherland, 1985). Despite the large metabolic demand for GDPmannose, the amounts present in all strains were small. This observation supports the idea of a tightly regulated flux of GDP-mannose through the GMD enzyme, probably by allosteric effectors, which is consistent with the observation that GDP-mannose concentrations are 
constant during exponential growth but fall during stationary phase when metabolic activity and therefore metabolite pool sizes are likely to decline.

In conclusion, our study has provided firm metabolic evidence that the activity of GMD regulates the flux of metabolites through the alginate pathway. The total available activity of GMD is certainly regulated by transcriptional control and may also be modulated by allosteric effectors. The activity of the enzyme is tightly regulated and this emphasizes the role which GMD plays as the key commital step for alginate biosynthesis in mucoid $P$. aeruginosa.

We gratefully acknowledge the receipt of a Post-Graduate Scholarship (to P. J. T.) from the Cystic Fibrosis Research Trust (UK). It is a pleasure to thank Dr J. R. W. Govan, University of Edinburgh, for his interest and the gift of isogenic strains of $P$. aeruginosa.

\section{References}

Anastassiou, E. D., Mintzas, A. C., Konuavis, C. \& DimitraCOPOULIS, G. (1987). Alginate production by clinical non-mucoid Pseudomonas aeruginosa strains. Journal of Clinical Microbiology 25, 656-659.

Berry, A., Devault, J. D. \& Chakrabarty, A. M. (1989). High osmolarity is a signal for enhanced alg $D$ transcription in mucoid and non-mucoid Pseudomonas aeruginosa strains. Journal of Bacteriology 171, 2312-2317.

Blumenkrantz, N. \& Asboe-Hansen, G. (1973). New method for the quantitative determination of uronic acids. Analytical Biochemistry 54, $484-489$.

BRADFord, M. M. (1976). A rapid and sensitive method for the quantitation of microgram quantities of protein utilizing the principle of protein-dye binding. Analytical Biochemistry 72, 248-254.

Darzins, A., Wang, S. K., Vanags, R. I. \& Chakrabarty, A. M. (1985). Clustering of mutations affecting alginic acid biosynthesis in mucoid Pseudomonas aeruginosa. Journal of Bacteriology 164, 516-524.

DeRETIC, V. \& KONYECSNI, W. M. (1989). Control of mucoidy in Pseudomonas aeruginosa; transcriptional regulation of $\operatorname{alg} R$ and identification of the second regulatory gene algQ. Journal of Bacteriology 171, 3680-3688.

Deretic, V., Gill, J. F. \& Chakrabarty, A. M. (1987a). Pseudomonas aeruginosa infection in cystic fibrosis; nucleotide sequence and transcriptional regulation of the algD gene. Nucleic Acids Research $15,4567-4581$

Deretic, V., Gill, J. F. \& Chakrabarty, A. M. (1987b). Gene alg $D$ encoding GDP-mannose dehydrogenase is transcriptionally activated in mucoid Pseudomonas aeruginosa. Journal of Bacteriology 169. 351-358.

Deretic, V., Dikshit, R., Konyecsni, M., Chakrabarty, A. M. \& MisRA, T.K. (1989). The algR gene which regulates mucoidy in Pseudomonas aeruginosa belongs to a class of environmentally responsive genes. Journal of Bacteriology 171, 1278-1283.

Deretic, V., Govan, J. R. W., Konyecsni, W. M. \& Martin, D. W. (1990). Mucoid Pseudomonas aeruginosa in cystic fibrosis: mutations in the muc loci affect transcription of the $\operatorname{alg} R$ and $\operatorname{alg} D$ genes in response to environmental stimuli. Molecular Microbiology 4, $189-196$

Deretic, V., Mohr, C. D. \& Martin, D. W. (1991). Mucoid Pseudomonas aeruginosa in cystic fibrosis; signal transduction and histone-like elements in the regulation of bacterial virulence. Molecular Microbiology 5, 1577-1583.

Devault, J. D., Berry, A., Misra, T. K., Darzins, A. \& ChakraBARTY, A. M. (1989). Environmental sensory signals and microbial pathogenesis: Pseudomonas aeruginosa infection in cystic fibrosis. Biotechnology 7, 352-357.
Dubois, M., Giles, K. A., Hamilton, J. K. Rebers, P. A. \& Smith, F. (1956). Colorimetric method for determination of sugars and related substances. Analytical Chemistry 28, 350-356.

DutTa, D. K. \& O’Donovan, G. A. (1987). Separation and quantitation of bacterial ribonucleoside-triphosphates extracted with trifluoroacetic acid, by anion-exchange high performance chromatography. Journal of Chromatography 385, 119-124.

Evans, L. R. \& Linker, A. (1973). Production and characterization of the slime polysaccharide of Pseudomonas aeruginosa. Journal of Bacteriology 116, 915-924.

Feingold, D. S. \& Franzen, J. S. (1981). Pyridine nucleotide-linked four electron transfer dehydrogenases. Trends in Biochemical Sciences 6, 103-105.

FERSht, A. (1985). Enzyme Structure and Function, pp. 263-290. Oxford: Freeman.

Fiahlo, A. M., Zielinski, N. A., Fett, W. A., Chakrabarty. A. M. \& BERRY, A. (1990). Distribution of alginate gene sequences in the Pseudomonas rRNA homology group I-Azomonas-Azotobacter lineage of superfamily B prokaryotes. Applied and Environmental Microbiology 56, 436-443.

FlynN, J. L. \& Ohman, D. E. (1988). Use of gene replacement cosmid vector for cloning alginate conversion genes from mucoid and nonmucoid Pseudomonas aeruginosa strains: alg $S$ controls expression of algT. Journal of Bacteriology, 170, 3228-3236.

FyFe, J. A. M. \& Govan, J. R. W. (1980). Alginate synthesis in mucoid Pseudomonas aeruginosa; chromosomal locus involved in control. Journal of General Microbiology 119, 413-450.

GoldBerG, J. B. \& Ohman, D. E. (1987). Construction and characterization of Pseudomonas aeruginosa alg $B$ mutant; role of alg $B$ in high level production of alginate. Journal of Bacteriology 169, 1593-1602.

Govan, J. R. W. (1988). Alginate biosynthesis and other unusual characteristics associated with the pathogenesis of Pseudomonas aeruginosa in cystic fibrosis. In Bacterial Infections of Respiratory and Gastrointestinal Mucosae (Special Publication of the Society of General Microbiology, vol. 24), pp. 67-96. Edited by W. Donachie, E. Griffiths \& J. Stephen. Oxford: IRL Press.

Govan, J. R. W. (1990). Characteristics of mucoid Pseludomonas aeruginosa in vitro and in vivo. In Pseudomonas Infection and Alginates: Biochemistry, Genetics and Pathology, pp. 50-75. Edited by P. Gacesa \& N. J. Russell. London: Chapman \& Hall.

Govan, J. R. W. \& Harris, G. S. (1986). Pseudomonas aeruginosa and cystic fibrosis: unusual bacterial adaptation and pathogenesis. Microbiological Sciences 3, 302-308.

Hobbie, J. E., Daley, R. I. \& Jasper, S. (1977). Use of nucleopore filters for counting bacteria by fluorescence microscopy. Applied and Environmental Microbiology 33, 1225-1228.

Holloway, B. W., Krishnapillai, V. \& Morgan, A. F. (1979). Chromosomal genetics of Pseudomonas. Microbiological Reviews 43. 73-102.

Kato, J. \& Chakrabarty, A. M. (1991). Purification of the regulatory protein AlgR 1 and its binding in the far upstream region of the alg $D$ promoter in Pseudomonas aeruginosa. Proceedings of the National Academy of Sciences of the United States of America 88, 1760-1764.

Kelly, N. M., MacDonald, M. H., Martin, N., Nicas. T. \& HANCOCK, R. E. W. (1990). Comparison of the outer membrane protein and lipopolysaccharide profiles of mucoid and nonmucoid Pseudomonas aeruginosa. Journal of Clinical Microbiology 28 , 2017-2021.

KonyeCSNI, W. M. \& Deretic, V. (1990a). DNA sequence and expression analysis of $\operatorname{alg} P$ and $\operatorname{alg} Q$, component of the multigene system transcriptionally regulating mucoidy in Psewdomonas acruginosa: algP contains multiple direct repeats. Journal of Bacteriolog! 172, 2511-2520.

KonyeCSNI, W. M. \& Deretic, V. (1990 b). A prokaryote regulatory factor with a histone H1-like carboxy terminal domain: clonal variation of repeats within $\operatorname{alg} P$, a gene involved in regulation of mucoidy in Pseudomonas aeruginosa. Journal of Bacteriolog. 172. $5544-5554$

LiN, T. Y. \& Hassid, Z. (1966). Pathway of alginic acid synthesis in the marine brown alga Fucus gardneri (Silva). Journal of Biological Chemistry 241, 5284-5297.

MiYamoto, I. \& NAGASE, S. (1981). A simple and rapid electrophoretic 
method for the separation of glucuronic acid and iduronic acid. Analytical Biochemistry 115, 308-310.

Mohr, C. D., Hibler, N. S. \& Deretic, V. (1991). AlgR, a response regulator controlling mucoidy in Pseudomonas aeruginosa, binds to the FUS site of the alg $D$ promoter located unusually far upstream from the mRNA start site. Journal of Bacteriology 173, 5136-5143.

Narbad, A., Russell, N. J. \& Gacesa, P. (1988). Radiolabelling patterns in alginate of Pseudomonas aeruginosa synthesised from specifically-labelled ${ }^{14} \mathrm{C}$ monosaccharide precursors. Microbios $\mathbf{5 4}$, 171-179.

Narbad, A., Gacesa, P. \& Russell, N. J. (1990). Biosynthesis of alginate. In Pseudomonas Infection and Alginates. Biochemistry, Genetics and Pathology, pp. 181-205. Edited by P. Gacesa \& N. J. Russell. London: Chapman \& Hall.

Ohman, D. E. \& Chakrabarty, A. M. (1981). Genetic mapping of chromosomal determinants for the production of the exopolysaccharide alginate in a Pseudomonas aeruginosa cystic fibrosis isolate. Infection and Immunity 33, 142-148.

Ohman, D. E. \& Chakrabarty, A. M. (1982). Utilization of human respiratory secretions by mucoid Pseudomonas aeruginosa of cystic fibrosis origin. Infection and Immunity 37, 662-669.

Ohman, D. E., Goldberg, J. B. \& Flynn, J. L. (1990). Molecular analysis of the genetic switch activating alginate production. In Pseudomonas; Biotransformation, Pathogenesis and Evolving Biotechnology, pp. 28-35. Edited by S. Silver, A. M. Chakrabarty, B. Iglewski \& S. Kaplan. Washington, DC: American Society for Microbiology.

PHILLIPS, J. (1969). Identification of Pseudomonas aeruginosa in the clinical laboratory. Journal of Medical Microbiology 2, 9-16.

Piggott, N. H., Sutherland, I. W. \& Jarman, T. R. (1981). Enzymes involved in the biosynthesis of alginate in Pseudomonas aeruginosa. European Journal of Applied Microbiology and Biotechnology 13, 179-183.

Pindar, D. F. \& Bucke, C. (1975). The biosynthesis of alginic acid by Azotobacter vinelandii. Biochemical Journal 152, 617-622.

Priess, J. (1964). Sugar nucleotide reactions in Arthrobacter. Part II. Biosynthesis of guanosine-diphosphomannuronate. Journal of Biological Chemistry 239, 3127-3132.

PRIESS, J. (1966). GDP-mannose dehydrogenase from Arthrobacter. Methods in Enzymology 8, 285-287.

PreIss, J. \& WoOD, E. (1964). Sugar nucleotide reactions in Arthrobacter. Part I. Guanosine diphosphate mannose pyrophosphorylase purification and properties. Journal of Biological Chemistry 239. 3119-3126.

Pugashetti, B. K., Vadas, L., Pritar, H. S. \& Feingold. D. S. (I983), GDP-mannose dehydrogenase and biosynthesis of alginate-like polysaccharide in a mucoid strain of Pseudomonas aeruginosa. Journal of Bacteriology 153, 1107-1110.

Randerath, E. \& Randerath, K. (1964). Resolution of complex nucleotide mixtures by two dimensionl anion-exchange thin-layer chromatography. Journal of Chromatography 16, 126-129.

Roychoudhury, S., May, T. B., Gill, J. F., Singh, S. K., Finngold, D. S. \& Chakrabarty, A. M. (1989). Purification and characterization of GDP-mannose dehydrogenase, a key enzyme in the biosynthesis of alginate by Pseudomonas aeruginosa. Journal of Biological Chemistry 264, 9380-9385.

Russell, N. J. \& GACESA, P. (1988). Chemistry and biology of the alginate of mucoid strains of Pseudomonas aeruginosa in cystic fibrosis. Molecular Aspects of Medicine 10, 1-91.

Russell, N. J., Tatnell, P. J. \& Gacesa, P. (1992). The regulation of alginate biosynthesis by mucoid Pseudomonas aeruginosa. In Cistic Fibrosis, Basic and Clinical Research, pp. 81-92. Edited by N. Høiby \& S. S. Pedersen. Amsterdam: Excerpta Medica.

Sherbrock-Cox, V., Russell, N. J. \& Gacesa, P. (1984). The purification and chemical characterization of the alginate present in the extracellular material produced by mucoid strains of Psetdomonas aeruginosa. Carbohydrate Research 135, 147-154.

Sutherland, I. W. (1985). Biosynthesis and composition of Gramnegative bacterial extracellular and wall polysaccharides. Annual Review of Microbiology 39, 243-270.

Trevelyan, W. E., Procter, D. P. \& Harrison, J. S. (1950). Detection of sugars on paper chromatograms. Nature, London 166, 444445.

Woodland, H. R. \& Pestell, R. Q. W. (1972). Determination of the nucleoside triphosphate contents of eggs and oocytes of Xenopus laevis. Biochemical Journal 127, 597-605.

WozniaK, D. J. \& Ohman, D. E. (1991). Pseudomonas aeruginosa $\mathrm{AlgB}$, a two component response regulator of the $\operatorname{ntr} C$ family, is required for $\operatorname{alg} D$ transcription. Journal of Bacteriolog! 173, $1406-1413$

Zielinski, N. A., Devault, J. D., Roychoudhury, S., May, T. B., Kimbara, K., Kato, J., Shinabarger, D., Kitano, K., Berry, A., MisRa, T. K. \& Chakrabarty, A. M. (1990). Molecular genetics of alginate biosynthesis. In Pseudomonas; Biotransformation. Pathogenesis and Evolving Biotechnology, pp. 15-27. Edited by S. Silver, A. M. Chakrabarty, B. Iglewski \& S. Kaplan. Washington, DC: American Society for Microbiology. 